Summer 2007

\title{
Understanding Interpersonal Interaction in an Online Professional Development Course
}

Rod P. Githens

University of Illinois at Urbana-Champaign, rgithens@pacific.edu

Follow this and additional works at: https://scholarlycommons.pacific.edu/ed-facarticles

Part of the Business Administration, Management, and Operations Commons, Education Commons, and the Organization Development Commons

\section{Recommended Citation}

Githens, R. P. (2007). Understanding Interpersonal Interaction in an Online Professional Development Course. Human Resource Development Quarterly, 18(2), 253-274. DOI: 10.1002/hrdq.1202

https://scholarlycommons.pacific.edu/ed-facarticles/101 


\title{
Understanding Interpersonal Interaction in an Online Professional Development Course
}

\author{
Rod P. Githens \\ University of Illinois at Urbana-Champaign
}

An edited version of this paper was published as:

Githens, R. P. (2007). Understanding interpersonal interaction in an online professional development course. Human Resource Development Quarterly, 18(2), 253-274.

\begin{abstract}
This qualitative case study was designed to examine how interpersonal interaction benefited (and did not benefit) participants in an online professional development course. In recent years, elearning courses in workplace and organizational settings have begun to include interaction and dialogue among participants. This case study is an in-depth exploration of interpersonal interaction and social presence within one such course. Notable findings include (a) participants valued the sharing of specific case-based knowledge by fellow participants, (b) some participants valued professional socialization with others in the field, (c) enthusiastic learners revealed complex and contradictory perspectives regarding interpersonal interaction, (d) facilitators needed to model social presence for participants, (e) some "inactive" participants were actually engaged, and (f) learners may seek online courses for purposes of intellectual safety.
\end{abstract}

Organizations increasingly recognize the value of creative, right-brained thinking, even in traditionally analytical occupations and in work previously thought of as routine. Most roles in today's organizations require analytical thinking, creativity, and experience-based intuition (Dreyfus \& Dreyfus, 1986). Learning programs dominated by behaviorist learning methods are unlikely to encourage creative thinking and collaborative sharing between individuals, which are necessary to move beyond analytical rule-based thinking. Human resource development (HRD) professionals should be aware of this increasing need to integrating deeper, reflective thinking into workplace learning programs (Smith, 2006; Waight, 2005). The encouragement of creativity and group sharing can help individuals question organizational norms through critical reflection (e.g., Harvey, 2004; Waddill, 2006), which ultimately leads to more innovative organizations.

In education, researchers and practitioners have recognized the importance of social and collaborative learning over the past 20 years. Online learning, especially in higher education settings, has reflected this shift with many programs including opportunities for interpersonal interaction and collaboration. These approaches provide a way of utilizing group problem solving, experimentation, and the social construction of knowledge (Koschmann, 1996). However, online learning programs in workplaces have not recognized these social and collaborative aspects as rapidly as academic programs. In many organizations, "e-learning” has been seen as providing employees with solitary "read and click" computer tutorials, which emphasize reading slides and taking short quizzes. Results from these e-learning programs have been questionable due to the primary emphasis on recalling facts (Garrison \& Anderson, 2003).

E-learning systems like those described above have been widely implemented because of their flexibility and cost savings compared to face-to-face programs (see Macpherson, Elliot, 
Harris, \& Homan, 2004). However, poor outcomes and low completion rates have resulted in organizations adding more socially interactive components in order to encourage more authentic learning experiences (e.g., Murphy, 2001; Salopek, 2004). As HRD practitioners attempt to implement interpersonally interactive programs, they need to understand the complexities of interpersonal interaction in e-learning. Under what conditions does interaction benefit participants? Which participants get the least benefit from interaction? Through a case study of an online professional development course, I provide some insights into these questions.

\section{Research on Social Dimensions in E-learning}

The effect of social interdependence (i.e., the sharing of group goals and a collective sense of success) has been addressed in over 650 experimental and correlational studies since 1898 (Johnson \& Johnson, 2004). Johnson and Johnson's meta-analysis of these social interdependence studies (primarily involving face-to-face learning settings) found a statistically significant advantage when comparing learning in cooperative settings to learning in noncooperative settings. Studies in online settings have also shown some positive relationships between social presence and measures of learning (Jiang \& Ting, 2000; Johnson \& Johnson, 2004; Picciano, 2002; Richardson \& Swan, 2003). However, these quantitative studies have revealed complex relationships. Measures of social presence do not always correlate with measures of learning.

Picciano's (2002) study of an online graduate course illustrates some of these complexities. On written assignments, students who made few bulletin board postings in the course did not do as well as those who actively participated. However, the less participative students performed as well as the others on the multiple-choice exam. This finding suggests that those making fewer postings (e.g., shy students) may be engaged with the course (i.e., through reading other's postings), but may choose not to share their own thoughts with the group. Picciano's study did not explore these issues further. Unbeknownst to the students, Poole (2000) tracked the number of times students read each other's postings in her study of an online graduate course. Some of the students who posted few messages themselves actively read others' messages throughout the course. These findings may be partially explained through Sutton's (2001) concept of vicarious interaction in computer-mediated communication (CMC). Vicarious interaction occurs "when a student actively observes and processes both sides of a direct interaction between two other students or between another student and the instructor" (Sutton, 2001, p. 227). This concept is familiar to facilitators/teachers in face-to-face settings. Further research is needed to understand the multifaceted issue of vicarious learning in online settings. Swan and Shea concluded, "whether and how social interaction might (or might not) affect learning online is clearly an important area for future research” (2005, p. 248). Interpersonal interaction, in general, is a complex aspect of e-learning in both higher education and organizational settings.

\section{Theoretical Lens}

Garrison and Anderson's (2003) community of inquiry model serves as the primary framework through which I view interpersonal interaction in e-learning. This framework for interpersonally interactive e-learning is represented by a three-circle Venn diagram, consisting of cognitive presence, teaching presence, and social presence. According to the model, enhanced learning occurs through the interaction of each of these three elements (Garrison, Anderson, \& Archer, 1999). This model emphasizes learning through communication and dialogue, as 
opposed to using educational methods that rely on familiarization with procedures and completion of assignments.

Teaching presence and social presence primarily serve to achieve the ultimate goal of cognitive presence in e-learning. The concept of cognitive presence is defined as "the extent to which the participants in...a community of inquiry are able to construct meaning through sustained communication” (Garrison et al., 1999, p. 89). Garrison and Anderson's inclusion of teaching presence illustrates the fundamental role that teachers have in their model of learning. As mentioned earlier, some e-learning programs seek to eliminate the role of human facilitator.

Social presence is a major focus throughout this study. Garrison et al. define social presence as "the ability of participants in a community of inquiry to project themselves socially and emotionally, as 'real' people (i.e., their full personality)” (1999, p. 94). Adequate social presence in a community of inquiry "supports cognitive objectives through its ability to instigate, sustain, and support critical thinking” (Rourke, Anderson, Garrison, \& Archer, 2001, The Community of Inquiry Model, \2) by encouraging a safe place to engage in meaningful interactions (Haythornthwaite \& Bregman, 2004). In other words, the educational value of interpersonal interaction is greatly enhanced when social presence occurs. Rourke, Anderson, and Garrison (2001) describe three types of social presence in online settings: (a) affective responses (e.g., the use of emotions and humor), (b) interactive responses (e.g., referring to others' messages, quoting), and (c) cohesive responses (e.g., socializing, referring to each other by name, using "we” when referring to the group). Social presence is not the ultimate goal of communities of inquiry; however, it is instrumental in their development. Without social presence, communities of inquiry are unlikely to form (Salmon, 2003). Due to the centrality of interpersonal interaction, this model of online learning may not be appropriate in all settings, depending on specific goals and preferences.

\section{Overview of the Study and Methods}

In this study, I examine "Current Issues" (all names are pseudonyms), an online professional development course for adults working in the rehabilitation and disabilities services field. I aim for an in-depth exploration of the issues surrounding interpersonal interaction and social presence in this e-learning course. As explained above, interpersonal interaction that includes social presence is seen as an integral component in allowing for meaningful online learning experiences. The overarching concern of this study is how does interpersonal interaction benefit (and not benefit) participants in this course? Additionally, I examine other relevant themes that emerged while exploring this question.

\section{Qualitative Case Study Approach}

Due to the complex nature of interpersonal interaction in e-learning, I utilize a qualitative case study approach. This approach allows for exploring the intricacies of a single program or course (Stake, 1995). Some quantitative data are reported; however, the main focus is on narrative description and interpretation of the case and its actors. By relying on observation and interpretation, I present multiple perspectives that exist within this case (Stake, 1995), providing a more in-depth understanding of the issues surrounding interpersonal interaction in this program. My methodological approach of qualitative case study research is influenced by the theoretical tradition of "weak" constructionism (Schwandt, 2000). This moderate form of constructionism provides a middle ground that allows for recognizing the social construction of reality, while still seeking as much objectivity as possible. 
Through member checking and using multiple sources and types of data, I sought to minimize misrepresentation of participants and their experiences. The notion of triangulation or crystallization expands on this idea. Like crystals, our research, "depends on how we view it, how we hold it up to the light or not” (Janesick, 2000, p. 392). As I sought multiple sources of information, the case was seen in different ways and grew more complex, like a crystal.

\section{Setting}

Current Issues is a six-week non-credit course in Continuing Education Online (CE Online), part of a federally funded program that provides assistance and continuing education opportunities to rehabilitation and disabilities service providers. Most providers work for government agencies or non-profit organizations. This course dealt with employment support for individuals with mental disabilities, which is considered an underexplored and "cutting-edge” topic in the field. Course facilitation occurred through the following media: an asynchronous discussion board, synchronous teleconferences (during the second and fifth weeks of the course), written assignments, and static course content. The course was moderated, meaning there were professional guides/facilitators for the participants. Interpersonal interaction has become integral to the requirements of this and other CE Online courses, as participants have asked for more interaction and less focus on quizzes and assignments. Participants' needs were carefully considered, since completion rates have been a concern for the program's staff. Approximately $50 \%$ of participants in other CE Online courses choose to drop out. The completion rate of this course was $64 \%$ (i.e., 11 out of 17 participants finished the course).

This case study started six weeks after the course concluded. All course materials and online conversations had been archived. The major concern in conducting a delayed study is the inability to observe participants and facilitators as the course was proceeding. However, there are advantages in doing a case study of an archived course. Most importantly, the program staff was able to help identify salient issues by reflecting on their experience and knowledge of this particular course and the course participants. Second, since the case study started after the course concluded, the course proceeded without interference from an outside researcher.

\section{Case Study Issues}

Stake (1995) explains that the identification of “issues” provides for more focus on the phenomena examined in case study research. He advocates identifying issues of intrinsic interest to the case itself, to provide for more meaningful inquiry. The issues developed for this study show an interest in the particularities of the case, while being informed by broader research ideas. They were developed after three meetings with CE Online staff members, but were refined as the study progressed. A better understanding of both the case and the general goal of the study (i.e., to have a greater understanding of how interpersonal interaction does and does not benefit participants) will result from exploring these issues that emerged from the program:

1. Whether social presence encouraged student engagement with others.

2. Whether participants were primarily interested in gaining access to static course materials.

3. Whether participants with less standing (i.e., those with less education or experience) engaged in interpersonal interaction at the same level as others in the class.

4. Whether the active participants acted as a community of learners.

Although these issues helped to guide the study, they should not be seen as formal questions to be answered directly in this article. Instead, the issues are embedded in the findings of the study. 


\section{Methods of Data Gathering/Analysis}

It is difficult to separate data collection and data analysis in many approaches to qualitative research (Patton, 2002; Stake, 1995). In this study, both occurred simultaneously in order to allow for a more fluid and emergent inquiry. I pre-determined some of the data collection methods; however, other methods emerged as the data collection progressed. The primary methods for gathering data included (a) interviews with course facilitators/program staff, (b) examination of archived synchronous and asynchronous discussions, (c) examination of course materials/documents, (d) interviews with course participants, and (e) analysis of the course evaluation results.

I conducted interviews with the course facilitators and five of the participants in order to actively involve them in constructing meaning from the archived course (see Tables 1 and 2 for more information). As mentioned earlier, I met with the CE Online staff three times to develop the issues of intrinsic interest to this case. Stake (1995) explains that "emic issues" or "issues of the actors, the people who belong to the case" (p. 20) emerge by gaining familiarity with the case. I began this process through collaboration with the program's staff. After the third meeting, the "emic issues" were compared against the general research question (i.e., the instrumental reason for doing the study) in order to refine the issues examined in this case study.

Table 1

CE Online Staff

\begin{tabular}{lll}
\hline Pseudonym & Position & Communication for this study \\
\hline Beth & Facilitator/Instructor & Three face-to-face interviews/email \\
Cynthia & Facilitator/Instructor & Two face-to-face interviews/email \\
David & $\begin{array}{l}\text { Program Coordinator/ } \\
\text { Asynchronous Facilitator }\end{array}$ & Two face-to-face interviews/email \\
Eunyoung & Technical Assistant & Three face-to-face interviews/email \\
Tim & Program Director & One face-to-face interview/email \\
\hline
\end{tabular}

Next, an analysis of online and written course materials provided me with an understanding of the case. All asynchronous and synchronous discussions were reviewed in chronological order. These observations allowed me to experience the discussion in a similar manner to the participants. A process of iteratively reading data, taking notes, compiling narratives, and identifying themes occurred throughout the analysis. Although initial issues of the study were already identified, a specific coding scheme was developed primarily by using inductive analysis throughout the data collection process (Patton, 2002). As themes emerged, notes and descriptions were made to capture them using a thematic coding process. As the process evolved, specific instances of themes were recorded to track the source (e.g., discussion board, teleconference), the person(s) involved, and a brief description of the event. Deviant cases or contradictory accounts were also sought (Flyvbjerg, 2004; Stake, 1995), which can be a major strength of qualitative case study. I report these contradictory perspectives throughout the article. Deductive analysis was used for identifying instances of social presence and teaching presence (see "Theoretical Lens" section, above), which complemented the inductive analysis. Course documents/correspondence (e.g., welcome letters), interviews (see below for details), and the course evaluation questionnaire were analyzed using the same inductive/deductive process. 
In addition to qualitative analysis, tracking the number of messages posted each week by individual participants provided a gauge of each participant's level of interactivity throughout the course. This process enabled me to have a weekly measure of which people were posting (1) required weekly messages (to start a thread), (2) required responses to others' messages, (3) extra comments, and (4) private conference messages for the course facilitators.

For the participant interviews, I used purposeful sampling to select those who shed the most light on the issues of this case (see Table 2 for participant details). In particular, the archived discussions and teleconferences provided information that allowed me to use the maximum variation sampling strategy (Patton, 2002) to solicit participants with divergent perspectives and experiences. Course dropouts were asked to participate in an interview, but none consented. Four of the participants were interviewed by telephone, in 30-45 minute semistructured interviews. Immediately after each interview, I wrote an interpretation/summary, to aid in the data analysis process. A fifth participant, Patricia, provided a more in-depth and complex understanding of the case. She was interviewed in person (in a two-hour interview), at her work site. As part of the interview process, I observed her as she viewed the course content and past online discussions, while "thinking aloud" (Nielsen, 1993; Patton, 2002). This process of cued recall allowed the participant to interpret and reflect upon her original experiences in the course, providing insight into the events that occurred. As mentioned above, interviews were analyzed using the same analysis process as was used for the online and written course materials. Follow-ups to the interviews were conducted via email (e.g., for clarifications from interviews, to ask additional demographic questions). For participants not interviewed, demographic and other general information was sought through email. Throughout the data collection process, I engaged with the program staff by having multiple conversations and email exchanges with them as questions arose. I also had a one-hour semi-structured interview with Beth (one of the course facilitators), near the conclusion of the data analysis process.

Table 2

Course participants mentioned by name in this study

\begin{tabular}{|c|c|c|c|c|}
\hline Pseudonym & $\begin{array}{l}\text { Work experience } \\
\text { in disability/ } \\
\text { rehabilitation } \\
\text { services }\end{array}$ & Education & $\begin{array}{l}\text { Online course } \\
\text { experience }\end{array}$ & $\begin{array}{l}\text { Communication } \\
\text { for this study }\end{array}$ \\
\hline Angela & 5 years & $\begin{array}{l}\text { High school } \\
\text { diploma }\end{array}$ & $\begin{array}{l}\text { Plans to start an } \\
\text { online courses for an } \\
\text { associate's degree }\end{array}$ & $\begin{array}{l}\text { Telephone } \\
\text { interview/email }\end{array}$ \\
\hline Carrie & 7.5 years & $\begin{array}{l}\text { Master's degree } \\
\text { in this field }\end{array}$ & None & Email \\
\hline Connie & 7 years & $\begin{array}{l}\text { Bachelor's degree } \\
\text { in psychology }\end{array}$ & $\begin{array}{l}\text { Second online course } \\
\text { through CE Online }\end{array}$ & $\begin{array}{l}\text { Telephone } \\
\text { interview/email }\end{array}$ \\
\hline Donna & Unknown & Unknown & Unknown & None \\
\hline Jane Klein & 7.5 years & Some college & $\begin{array}{l}\text { Second online course } \\
\text { through CE Online }\end{array}$ & $\begin{array}{l}\text { Telephone } \\
\text { interview/email }\end{array}$ \\
\hline Jodi & 1 year & $\begin{array}{l}\text { Master's degree } \\
\text { in business } \\
\text { administration }\end{array}$ & $\begin{array}{l}\text { Took part of an } \\
\text { online course through } \\
\text { a book retailer }\end{array}$ & $\begin{array}{l}\text { Telephone } \\
\text { interview/email }\end{array}$ \\
\hline
\end{tabular}




\begin{tabular}{|c|c|c|c|c|}
\hline Laura & 7 years & $\begin{array}{l}\text { Bachelor's in } \\
\text { management }\end{array}$ & $\begin{array}{l}\text { None. Now wants to } \\
\text { enroll in an online } \\
\text { degree program }\end{array}$ & Email \\
\hline $\begin{array}{l}\text { Patricia } \\
\text { (Pat) Cook }\end{array}$ & 3.5 years & Some college & None & $\begin{array}{l}\text { Face-to-face } \\
\text { interview/email }\end{array}$ \\
\hline Scott & Unknown & Unknown & Unknown & None \\
\hline $\begin{array}{l}\text { Sofia } \\
\text { (dropped } \\
\text { out) }\end{array}$ & Unknown & Unknown & Unknown & None \\
\hline
\end{tabular}

The CE Online staff administered an evaluation questionnaire at the conclusion of the course. It aimed to evaluate the effectiveness of the course and served as a developmental tool for the program and the staff. Although this case study was not considered in the design of the questionnaire, the open-ended questions provided data that were used to develop the interview guides, using the analysis process described above.

\section{Findings}

In reporting the case study findings, I begin with a narrative case description. The narrative description allows readers to understand the circumstances in which this study occurred in order to have a deeper contextual understanding of the case (Flyvbjerg, 2004; Stake, 1995). This description is presented primarily from my perspective as a reviewer/analyzer of the course documents, discussion board exchanges, and teleconferences. Next, I provide the results of the discussion board posting analysis and the course evaluation questionnaire. Lastly, I present the themes that emerged from the inductive/deductive data analyses.

\section{Narrative Case Description}

Getting started. After registering for the course, participants received an email message from the program's technical assistant, Eunyoung. The email contained a form letter from the program coordinator that included login/password information and a "course information guide," similar to a syllabus. When participants logged into the course, they saw a basic web page with photos of the program staff.

Also on the main course page, participants saw the six-week outline--one lesson for each week. Each lesson dealt with various aspects of employment support for individuals with mental disabilities. The lessons included online readings, review questions (to be posted to a private section of the discussion board for the facilitators to review), and discussion questions (designed to initiate discussion board conversations).

The participants and facilitators. The 17 participants were all from the Midwest and made references continually to their geographic locations (e.g., "here in northern Indiana”). It was apparent that they strongly identified with their diverse communities, which ranged from the suburbs of Chicago to rural and remote towns. A few of the participants stood out as being central to the activities of the course. For example, Jane Klein is a lone wolf caseworker in a very remote region of the upper Midwest. She had previously taken a course in the CE Online program. Her outgoing personality was apparent on the teleconferences. Connie was also very 
engaged in the course. She had previously taken a CE Online course and has been in the field for seven years. She lives and works in the suburbs of a major city. Carrie also stood out, sometimes dominating the teleconference conversations. She serves as the director of her agency, located in a small town. Of the participants, Carrie was the most highly educated in this field, with a master's degree.

Beth, Cynthia, and David were the facilitators for the course. Beth and Cynthia facilitated the synchronous teleconferences. Along with David, they reviewed assignments for a specific number of participants. Each of them works part-time in the CE Online program. Additionally, they all have professional work experience in this field and are pursuing doctoral degrees in the field. Cynthia is outgoing and boisterous, while Beth is quiet and reserved. David, very casual and relaxed, took a "behind-the-scenes" role in this course.

Early discussion board threads. During the first week, participants were asked to share online and written resources used in a certain aspect of their work. Jane made the first posting on the first day of the course. In a brief message, she listed several URLs and agency addresses that had been helpful to her. Within four days, two participants responded by saying which resources were particularly useful. There were several similar threads that week. Later in the week, Jane started an exchange with Scott, who had also posted some resources. "Scott, nice to meet you, thank you for the web sites. I like the hotlinks on the first site-very easy to use. Do you have any sites that target employment issues?" Without taking the lead from a course facilitator, Jane initiated a "two-way" conversation with Scott. In response, Scott said, "Hello Jane, good to meet you too.” He also supplied links to resources pertinent to Jane's request.

On the sixth day of class, Connie was confused about where to post her assignment and asked for clarification. She posted a message for Pat (another participant), but Scott voluntarily pitched in and told her where she needed to post the assignment. At this point, no staff member had posted to the board; 15 participant messages had been posted.

The first teleconference. Eleven participants and two facilitators attended the first teleconference, during the second week of the class. The beginning was a bit awkward as participants first entered the conference with little conversation. Then, Jane asked whether there was a toll-free number for participants to use. When Beth (one of the facilitators) explained that she could call back on the toll-free number, several participants immediately hung up and called back. Scott said, “That was a great question. Who asked that?” “Jane Klein, I'm cheap.” With the ice broken, the conversation then became more casual as participants continued to arrive. When Cynthia (the other facilitator) arrived, the conversation became even more relaxed since she continued with small talk in her outgoing manner. The group discussed the extreme cold in the upper Midwest, followed by ten minutes of technical and administrative questions.

The conversation shifted to the course subject matter, a discussion centered around stigma for people with psychiatric disabilities. The conversation gravitated toward community educational outreach. Laura, calling from Flint, MI, revealed, "I have bipolar disorder myself. I go and talk about my experiences. I educate people [with mental disabilities]. And they're more open with me because they know I'm not going to judge them or put any stigma on them." Throughout the call, several participants referred to psychiatric disabilities of their own or of family members. Some of the participants were very comfortable talking about this topic.

As Cynthia and Beth facilitated the conversation, most participants seemed willing to share information and experiences. Upon further analysis (i.e., looking at the number of 
instances that each person actually spoke), a couple participants were conspicuously quiet. Pat Cook later explained, “I didn’t even want to dial in. But, I knew that in order to get a completion, I had to do it. The very first session...I just sat there and listened. Cynthia was able to ask a question and get a reaction from people. That made your own mind start going. There were people on there with a lot more schooling than me. They had a lot more knowledge than I did and different experiences.”

Teleconference distractions. The conversations were not completely smooth. The first teleconference occurred over the noise of Sofia's cell phone (she was traveling during the call), with intermittent interruptions from a loud machine noise in the background and frequent coughing from another participant. Some participants became irritated by the distractions and asked that cellphones be banned on the next teleconference. The group decided against that proposal. As in many courses, there was also a participant who dominated the conversations. Carrie talked at length during both teleconferences and cut off Cynthia (a facilitator) on more than one occasion. In later interviews, participants expressed irritation regarding this domination of the teleconference.

After the first teleconference. In the days immediately following the first conference call, there were few meaningful exchanges on the discussion board. Most participants who responded to others' postings essentially said, "I agree” in two to three line responses (most messages that started each thread were quite detailed, as opposed to the responses within those threads). Additionally, socially interactive exchanges (e.g., referring to each other by name) almost completed ceased. Before the teleconference, most postings referred to other participants by name (e.g., "Hi Scott”).

Rough start to the second teleconference. During the fifth week, the second conference call had seven participants and two facilitators. It started out with Jane and two unidentified participants on the line. They heard the beep that indicated someone had hung up. Jane said, “They didn't want to talk to us.” The other person laughed and said "I guess” in a friendly tone. After twenty seconds of silence, two additional participants came in at the same time and were confused over who was facilitating the call. They both thought the other person was the facilitator. A third participant clarified the confusing situation by saying, "I don't think the conference person is on yet."

This awkward exchange preceded some discussion of whether everyone was in the right teleconference space. "We're all on our own," one participant said. Another said, "We can say we participated in the conference call without a facilitator." Jane offered, "I can call the other line on my cell phone.” Another said, "oh, that's a trick” (laughed). Jane responded, "I can multitask.” She followed-up with "Of course, my husband just laughed at me [for suggesting I can multitask]." This exchange was followed by the entry of the facilitators and discussion of some minor technology issues.

Feedback about the course. At the end of the second conference call, Cynthia asked the group to discuss their likes and dislikes about the course. Several talked about the information they liked in the course - they liked that the material was not too technical in nature. Some mentioned the helpfulness of free online resources that participants shared with each other. Several people also shared common struggles of working in this field in small communities and 
how they are innovative in piecing together services for their clients. Throughout the call, there were several interactive discussions between participants.

Cynthia said the discussion was going great, but that she wanted to open it up to other topics for the last 15 minutes. After a delay, Cynthia asked, “Anybody?” followed by laughter. After a joke about Cynthia's question, Jane said, “I’m really glad that I decided to take it. The information has been phenomenal” (emphasis added). She added that the online resources that participants shared were especially helpful for her, in her remote location. An unidentified person said, "It's been nice to see other perspectives. The teleconferences have been very helpful in getting other perspectives. It's been nice to know that we're not the only ones in that boat" (referring to problems with a specific government program mentioned during the teleconference). Carrie said that she misses the interaction with peers since she's no longer in graduate school. She said this course was an opportunity for her to experience a similar kind of interaction. As the discussion wrapped up, the call ended with people saying goodbye.

The end of the course. After the second teleconference, a posting made by Laura regarding evidence-based practice (a major new mandate by many state governments), caused a very lively, passionate set of detailed responses. Connie made the last posting on this topic. She closed her two-paragraph message by saying "At times I really worry if there is a future for our services. Only time will tell. Thanks for sharing the information re. your states and services."

\section{Discussion Board Posting Analysis}

For each of the six weeks in the course, participants were required to make a weekly posting regarding the lesson's topic and respond to two postings by other participants. Although the course welcome letter said, "Interaction with fellow students and the instructors in the threaded online discussions is where the greatest learning takes place," there was never any reinforcement of this idea by the instructors (i.e., in the teleconferences, on the discussion board). The Course Information Guide stated that participants were required to reply to at least two other participant responses for each lesson, but did not mention quality of responses or engaging in actual discussion. During the entire course, there were only two "non-required" postings on the main discussion board (one was a technical question). However, there were eleven non-required postings in the participants' private discussion areas, which were used for interaction with the facilitators. Beth, Cynthia, and David divided up the group, reviewed the work of their assigned participants, and provided private feedback. Ten of the 11 non-required postings in these private areas were responses to the facilitator's questions. In this space, Cynthia also reminded her participants if they were not making the required responses to others' postings each week. Facilitators asked participants specific questions about their assignments, how the course was going, and if they had any questions about the course. Some participants responded to the questions and others did not.

All 11 participants who completed the course made the six required postings (starting a thread). However, only Jane and Donna fulfilled the requirement to post two responses each week. Jane posted very short, one or two-sentence responses (with the exception of the first week). Generally, Donna posted more thoughtful, detailed responses. On the other hand, several participants, who did not technically fulfill the requirement, posted more thorough, thoughtful responses than the two who fulfilled the requirements. 


\section{Course Evaluation}

Eleven people completed the course, nine of which completed the standard CE Online evaluation questionnaire. The 23 Likert-scale questions produced no noteworthy findings for this study. The first open-ended question asked respondents what they liked most about the course. Five of the nine referred to the teleconferences or to contact with other people. For example, "I enjoyed being able to interact with the other students via email and over the phone." Another responded, "I found the conference calls to be a really good tool. It was very helpful to talk to other professionals and realize that we are all facing the same problems and have had similar experiences regarding topics such as the ticket to work and NISH.”

However, when asked what they liked least about the course, two participants referred to the discussion board assignments. For example, "I found it to be time consuming reading and replying to other classmates' application exercises.” In contrast to those who found the interaction beneficial, another participant said, "This was my first online course and I missed the classroom interaction and discussion on the topic. The phone conversations were useful but limited." When asked how the course should be changed, one person suggested adding an additional teleconference. Overall, participants found value in the interpersonal exchanges, but the exceptions are noteworthy.

\section{Themes}

Throughout the data collection process, significant themes emerged that help to answer the research questions, as well as introduce new questions. The iterative process of revising interview questions and document analysis methods continued as these themes emerged.

Importance of sharing case-based knowledge. In my early conversations with the CE Online staff, they identified the issue of whether participants and dropouts were primarily interested in seeking the information (i.e., static content) from the course. Since no dropouts participated in the study, that question remains partially unanswered. While searching for an answer among those who completed the course, a slightly different theme emerged.

All of the participants had a desire to learn what other organizations/agencies were doing and what other individuals had to share. This theme was present regardless of whether participants wanted to communicate directly with others. In other words, participants like Angela and Jodi had little desire to interact directly with other participants (explained further in the subsequent paragraphs). However, they both valued learning from others' experiences and stories (i.e., others' “cases”). Dreyfus and Dreyfus (1986) explain that case-based knowledge allows individuals to progress from rule-based beginners to competent performers to virtuoso experts. In other words, it is necessary to learn from concrete experience (from oneself or others) to move beyond the rule-based knowledge of a beginner (Flyvbjerg, 2004). In this course, participants heard and read about others' real-life experiences in addition to reading the static content, which was similar to textbook materials.

Four of the five interviewees reported they were initially focused on seeking information only from the static content. Three of those individuals eventually found value in the exchanges on the teleconferences (one of them also liked the discussion board exchanges). Two other participants, Jodi and Angela, preferred the exchanges of information and experiences on the discussion board, but did not find much value in the teleconferences. Angela did not attend either teleconference and Jodi only attended the second one (she enrolled in the course late). Jodi said, "Well, I'm a reader, so I really did enjoy having the hard copy (course readings) to 
read through and having the facts. But, reading the other experiences of what people have gone through was nice-people who are actually out there doing the job. The teleconference I attended didn't give me a whole lot. I could see how they would be real beneficial if they were really structured. But, it seemed like there were a lot of people wanting to say a lot of things." She elaborated further on the discussion board topics, "Reading others' postings was good because you got all of their experiences. It almost gave you a case study of each topic. I actually went through and read all of the postings."

It would be inaccurate to call Jodi and Angela "collaborative learners.” However, their initial desire to merely seek generalized information was replaced by recognition that they could learn from others' specific real-life experiences through the asynchronous discussion board. The other three participants valued learning from others' specific experiences and gradually placed more value in the interpersonal interaction with others. As the course progressed, they were still very interested in generalized information from the static course content. However, they found value in the sharing and dialogue among the group, especially through learning about others' real life experiences. The overarching theme of the importance of sharing case-based knowledge is intertwined throughout the other subsections that follow.

Socialization in the field. For most professionals, developing ties within their respective field is an important part of work life and professional development (for an example of building professional ties through an online master's degree program, see Kazmer, 2004; Kazmer \& Haythornthwaite, 2004). The informal process of professional socialization occurs through conversations with coworkers and colleagues, attending professional association meetings, and hearing "war stories" of others in the field. In this course, professional socialization with others in the field emerged as a benefit of the teleconferences. Based on the interactions that occurred, the teleconferences had more social presence than the discussion board. Social presence is one factor that allowed the professional socialization to occur. In general, participants recounted deep hesitance before taking part in the initial teleconference but were eventually pleased that they participated. Pat's comments represent several others' perspectives quite well, "I was really reluctant to do the conference call. But, there were enough people on there interacting, that it was really good. It was really interesting to sit on the phone and listen. I can't say that I missed out on anything not being face-to-face because of the two telephone sessions and the [asynchronous] discussion board. It's good to hear the others' experiences. It made me feel like I'm not alone with these issues. I might be able to use something that someone said to help one of my clients keep their job. I really thought the teleconference was a great idea, especially for an online course since you don't feel like you have communication with people.” For Pat, the vulnerability of going onto the conference call was eventually eased and the benefits of interacting with others in her field outweighed the vulnerability. This comfort was illustrated through her increased level of involvement during the last part of the second conference call. However, as mentioned earlier, Jodi attended the second teleconference, but remained unenthusiastic about it after completing the session. "I probably did more listening than I did talking because I wasn't sure who was there and what was going on.” Although she reported actively reading the discussion board postings, she had little interest in interaction and learning about the other participants in the course. For example, I asked whether she looked at the biographies and pictures of the participants. "I did for the instructors. I thought that was more important than the other folks.” It was apparent that socialization in the field was not a priority 
for Jodi, in this course. Although she valued reading about others' experiences, having direct interpersonal interactions with fellow participants was not a priority.

Jodi's experience was the exception (although an exception that should be noted). Eventually, most of the participants reported finding value in the teleconferences, especially valuing the collegial conversations. Although reluctant to participate initially, they recognized the importance of sharing ideas, sharing war stories, and hearing other "real” people's voices.

Conflicting attitudes from the learning enthusiasts. In exploring how interpersonal interaction benefited and did not benefit the participants in the course, it became clear that Jane and Connie stood out as active, engaged, and enthusiastic learners. However, their actions and perceptions toward the course highlight the complexity of identifying the benefits of interpersonal interaction.

Jane, from the beginning, was an enthusiastic online learner. She made the first discussion board posting, interacted with others on the discussion board very early, was the only person to post her picture to the biography page, and initiated early conversation when she arrived for the first teleconference. When I asked her about the most valuable component of the course, she said teleconferences and online readings were the most valuable. She elaborated immediately on the value of the phone conferences, "Because you're interacting with so many different people, it's interesting to find out what's happening in other parts of our state... and realize that we have the same problems here as other places."

When I asked Jane about the discussion board, she said, "I hate that part. Well, it's not that I hate it, it's the requiring us to reply to two people each week. That's fine, but half the time, you're like 'what do I say to this person? I don't even know them.'” She followed up by saying that not knowing the participants makes it harder to communicate through the discussion board, "It was better once we had the teleconference and you actually got to hear voices, but for me, it's hard. I'm a face-to-face person.” Jane later explained that she visited someone from a previous CE Online course, after interacting online. Because of her remote location, Jane was unable to take courses any other way. However, she sought out the face-to-face contact with the fellow participant when she was traveling in another part of her state.

Connie, another participant taking her second online course, was also an enthusiastic learner. During the teleconferences, she was very active, without being a dominator. Compared to the other participants, her postings and responses to others' discussion board messages were consistently the most thoughtful throughout the course. However, she told me that the discussion board was not valuable for her. "What I started finding through the webboard, since you had to participate so many times, I started giving some cheeseball answers just so that I had my participation done. I'd say 'oh, that's a great idea' [in response to someone's posting] regardless of whether I really thought that. I found myself just replying to meet the requirement." On the other hand, she later told me about an email conversation that was spawned with another participant because of a discussion board exchange. The out-of-class email conversation suggests that at least one discussion board exchange was meaningful to her.

The paradoxical experiences of these enthusiastic learners are illustrative of the mixed messages from the other participants' attitudes towards interpersonal interaction in online learning. Although these two individuals were very active in the course, both of them suggest that the quality of their exchanges were inferior to face-to-face conversations. Jane was talkative and social in the first week of the discussion board and on both teleconferences. However, she commented that she did not know the participants. Distance requirements made it difficult for 
Jane to travel to a face-to-face workshop, but her sociable personality carried over occasionally into this alternative learning setting. Connie appeared to be the most engaged participant in the course. However, she revealed that she felt many of her experiences were contrived.

Little social presence without facilitators' modeling. Garrison and Anderson (2003) explain that social presence usually needs to be modeled by the facilitators in order for participants to be comfortable engaging in socially-interactive exchanges. As explained earlier, social presence is seen as a key component to encouraging interactive dialogue among participants. While exploring whether social presence encouraged student engagement with others on the asynchronous discussion board, I found that social presence declined after the first teleconference. Before the first teleconference, the participants referred to each other by name and engaged in conversational-style exchanges on the discussion board. Surprisingly, exchanges of this type ceased (for the most part) after the first teleconference. Participants no longer referred to each other by name and they rarely made attempts to be friendly. On the other hand, discussion board participants were very open in revealing details about mental disabilities of themselves or of family members.

To explore this topic, I asked participants to explain how they interact through email on a daily basis and how their normal practices differ from discussion board experiences in this course. Pat explained that she varies her text and email messages, depending on the individual and the setting. "In this particular class, I think I was just more to the point. There's a time to be chatty and a time to not be chatty." Angela (who did not post any responses to others' messages) said, "On a board like this, I...well, expect it be more down to business. We're all here for the purpose of completing the course and learning. But, if people were more chatty and not straight to business, it wouldn't bother me." Participants often look to facilitators for guidance as to the appropriate level of interactivity. Beth, one of the facilitators, made a few friendly and interactive postings on the public portion of the discussion board. However, the facilitators were largely absent from the discussion board conversations. Beth explained that the board has been seen as the participants' domain. "I tend to make more comments in the beginning until I see how people are getting along...I don't know how that's perceived. I kind of worry that it might be perceived as ignoring them." The facilitators knowingly displayed little presence on the discussion board. Therefore, conveying a sense of social presence was not a concern.

Although modeled during the teleconferences, there was little modeling of social presence by the facilitators on the public section of the discussion board-intended as the primary medium for group communication during the course. Based on the events in the course, we can assume that students stopped displaying social presence because they saw the discussion board primarily as a place to post assignments and make required postings. The teleconferences were seen as the place to engage in dialogue.

Engagement by “inactive” participants. Picciano’s (2002) study made a suggestion that it may be incorrect to assume that "inactive" participants are, in fact, not engaged in the course. Angela and Jodi's experiences support that suggestion. Neither appeared to be very engaged, based on discussion board responses and teleconference activity. After deeper examination, I found that both preferred to sit on the sidelines of the conversation, but were actively "observing" the course. For example, Angela completed the course without attending either teleconference or responding to any messages from other participants on the discussion board (she did start her six required threads). However, she logged into the discussion board more than 
any other participant or facilitator, according to tracking records. She explained that she is a reserved person (online and offline), but found value in the discussion board. "I made sure I read every posting. I would also check it once a day, just to see if anyone else had posted. Everyone has different ways of dealing with issues and some of the things might be helpful for situations that I might be in. It's also helpful to see different areas where people get their information and what they’ve been through.” Angela's experiences further substantiate Picciano's suggestions regarding "inactive” participants.

Intellectual safety in being online. Three of the five participants that I spoke with (who had no college or university education in this field) said that they liked to "take things in," instead of saying a lot during the teleconferences (i.e., Angela, Jodi, Pat). Jodi and Pat consider themselves new to the field. Regarding the teleconferences, Jodi, who has been in the field less than a year said, "If I know what I'm talking about, I tend to have no problem saying things. In this course, since it's something new that I'm getting into, I felt like these folks had more of a professional background. I did a lot more listening."

As mentioned earlier, Pat explained that she did not want to participate in the teleconference initially. Pat was not a shy person. Starting with our first face-to-face encounter in the reception area of her agency, I found Pat to be very outgoing, in contrast to her reserved online demeanor. She became comfortable with the teleconference eventually, but thought others had more knowledge than her. Pat explained an experience she had in a face-to-face training program (affiliated with a university in her home state). After she attended the training program at the university, she felt very discouraged about the quality of her agency because a certain practice they use was considered barbaric by the professors leading the training program. "I came back and thought we were doing everything wrong. I was very discouraged." She has since concluded that they have to do what works with the resources available in her rural community. She referred to this bad experience multiple times during our interview.

These experiences raise additional questions about whether participants seek online courses specifically to find a safer, less threatening learning environment. Some online learners may think it is easier to "hide in the shadows" in an online course. If individuals are uncomfortable with a topic, they may seek out an online learning experience. I did not specifically address those issues in the study.

\section{Limitations}

\section{Conclusions}

Reflexivity, “the process of critical self-reflection on one's biases, theoretical predispositions, preferences, and so forth” (Schwandt, 2001, p. 224), helps researchers to continually acknowledge and be aware of factors shaping their interpretations. By reading the researcher's reflections on reflexivity, the reader has some insight into the unseen forces that lie beneath what is traditionally reported in social research. However, "coming clean” must be balanced with the danger of distracting from the main topic of the research (Fine, Weis, Weseen, \& Wong, 2000). By putting my reflections at the end of the report, I am attempting to balance my desire to "come clean" with the risk of distracting from the case study. However, I engaged in this reflexivity process throughout the study; it cannot compartmentalized into the latter stages of the research process. Additionally, my reflexivity process was much more complicated than what I can report here, due to space constraints. 
As for my biases, my experience teaching in and coordinating an online master's degree program influences my thinking about online learning. I am a cautious advocate for online learning, which undoubtedly influenced this study. Another bias is that I strongly advocate the inclusion of interpersonal interaction in e-learning. In my own practice, I encourage the use of interpersonal interaction as much as possible. For this study, I sought out CE Online specifically because its courses include interpersonal interaction. The program staff and I chose this specific course for the study because it had more asynchronous interaction than other courses in the program. I hoped and expected to find that asynchronous interaction was a major strength of the course and allowed for deep learning and reflection. However, as I explained earlier, the results were mixed and complicated. Flyvbjerg (2001) contends that a major strength of case study research is the intimacy in which preconceived notions can be contradicted. However, as with all case study research, the findings are not necessarily generalizable, which I discuss below. In this case study, I was intimately aware of the particulars of the case and found that my preconceived notions (and desires) did not necessarily unfold. From these findings, implications for practice emerged and additional research questions were raised.

\section{Implications for Practice}

Although this case study dealt with a particular course, in a particular setting, specific themes (outlined above) emerged from the experience of the participants in this course, when compared with related literature. These findings are not universally applicable to all e-learning settings. Considering the context of this study, readers must decide for themselves whether these themes apply to e-learning settings and courses in which they are familiar. The themes offer insights that can help practitioners reflect on how and whether to integrate interpersonal interaction into e-learning programs.

Recommendations emerged from the guiding question of the study by providing ways to integrate interpersonal interaction into online courses in order to benefit the participants. First, facilitators should encourage social presence and dialogue. Social presence is a key enabler of deeper educational goals in interpersonally interactive e-learning (Garrison \& Anderson, 2003; Salmon, 2003). This study supports Garrison and Anderson's and Salmon's work from elearning in higher education that concludes social presence should be modeled by instructors in order to help spawn its development (also see Aragon, 2003). Social presence was modeled by the facilitators in the synchronous teleconferences, but was rarely modeled on the asynchronous discussion board. In this course, facilitators simply lacked the knowledge that they should model exchanges of this nature. For example, Beth, one of the facilitators, was unsure what and how much she should post to the discussion board. Facilitators of e-learning, especially those in workplace and continuing education settings, sometimes assume that participants are not interested in engaging in socially-interactive exchanges. However, for courses to reach their full potential, social presence is an integral component. In this course, many participants appreciated the social connections and interpersonal communication, although they were focused initially on seeking information from the static content. Additionally, participants need guidance on how to engage in meaningful discussion board conversations. In formal courses like this one, initial leadership and illustration from the facilitator is essential (Garrison \& Anderson, 2003). In this course, most were unaware that the primary purpose of the discussion board is dialogue-more than supplying "the answer" to the posed question.

Second, program designers should avoid rigid participation requirements unless necessary. E-learning designers must carefully balance the need to encourage participation and 
the inclination to enact overly strict requirements that result in meaningless, mechanistic postings. In this course, the discussion board posting requirements (i.e., participants had to start one thread per week and respond to two postings per week) resulted in anxiety and irritation by some participants. Additionally, most failed to meet those requirements. Jane, who technically fulfilled the requirement, made very brief, unsubstantive comments. These findings support Garrison and Anderson's (2003) recommendation of using more broad, qualitative guidelines to encourage asynchronous participation, rather than strict requirements regarding the number of postings made (also see Benson, 2003). If the course facilitators emphasize asynchronous participation and explain what type of participation is valued (e.g., contributing to the dialogue, reflecting on others' postings), the value is more readily seen. On the other hand, the attendance requirement for the teleconferences was successful. Some participants were very reluctant to participate in the calls, but said they saw their value after attending to meet the course requirements. For the teleconferences, the initial attendance requirement appeared to be vital in sparking a sense of togetherness among the participants. Without the requirement, some participants indicated they would not have attended.

\section{Implications for Future Research}

This study provides empirical support for future research on exploring how interpersonal interaction benefits (and does not benefit) participants in online professional development courses. Also, the study raises further issues to explore. One major issue deals with exploring the factors and circumstances that encourage active engagement in asynchronous communication. Due to the complexities of e-learning in workplace settings (e.g., participants have full-time work responsibilities, no grades are assessed), what is required to encourage lively, engaging asynchronous discussions? Does more active facilitation increase genuine participation? Another issue to explore is whether the perceived safety in e-learning attracts learners who are reluctant to attend face-to-face sessions. If so, how should e-learning designers and facilitators account for this in their design/teaching strategies? A disappointment in this study was that no dropouts consented to be interviewed. Major questions remain regarding their reasons for dropping out. In future studies, efforts should continue to be made to convince dropouts to participate.

Although questions remain to be explored regarding interpersonal interaction, insight was gained through this study regarding what worked, what did not work, and what worked for some participants in this course. As HRD practitioners continue to recognize the value of collaboration and deeper reflective thinking, interpersonal interaction will become more integrated into e-learning courses. With this growth, there will be more opportunities for research in multiple types of organizations and settings. 


\section{References}

Aragon, S. R. (2003). Creating social presence in online environments. New Directions for Adult and Continuing Education, 100, 57-68.

Benson, A. D. (2003). Assessing participant learning in online environments. New Directions for Adult and Continuing Education, 100, 69-78.

Dreyfus, H. L., \& Dreyfus, S. E. (1986). Mind over machine: The power of human intuition and expertise in the era of the computer. New York: Free Press.

Fine, M., Weis, L., Weseen, S., \& Wong, L. (2000). For whom? Qualitative research, representations, and social responsibilities. In N. K. Denzin \& Y. S. Lincoln (Eds.), Handbook of qualitative research (2nd ed., pp. 107-131). Thousand Oaks, CA: Sage.

Flyvbjerg, B. (2001). Making social science matter: Why social inquiry fails and how it can succeed again. Oxford, UK: Cambridge University Press.

Flyvbjerg, B. (2004). Five misunderstandings about case-study research. In C. Seale, G. Gobo, J. F. Gubrium \& D. Silverman (Eds.), Qualitative research practice (pp. 420-434). London: Sage.

Garrison, D. R., \& Anderson, T. (2003). E-learning in the 21st century: A framework for research and practice. London: RoutledgeFalmer.

Garrison, D. R., Anderson, T., \& Archer, W. (1999). Critical inquiry in a text-based environment: Computer conferencing in higher education. The Internet and Higher Education, 2(2-3), 87-105.

Harvey, B. (2004). Chuck out the chintz? "Stripped floor" writing and the catalogue of convention: Alternative perspectives on management inquiry. Journal of European Industrial Training, 28(8/9), 669-675.

Haythornthwaite, C. A., \& Bregman, A. (2004). Affordances of persistent conversation: Promoting communities that work. In C. A. Haythornthwaite \& M. M. Kazmer (Eds.), Learning, culture and community in online education: Research and practice (pp. 129143). New York: Peter Lang.

Janesick, V. J. (2000). The choreography of qualitative research design. In N. K. Denzin \& Y. S. Lincoln (Eds.), Handbook of qualitative research (2nd ed., pp. 379-399). Thousand Oaks, CA: Sage.

Jiang, M., \& Ting, E. (2000). A study of factors influencing students' perceived learning in a web-based course environment. International Journal of Educational Telecommunications, 6(4), 317-338.

Johnson, D. W., \& Johnson, R. T. (2004). Cooperation and the use of technology. In D. H. Jonassen (Ed.), Handbook of research on educational communications and technology (2nd ed., pp. 785-811). Mahwah, NJ: Erlbaum.

Kazmer, M. M. (2004). Disengaging from the online community. In C. Haythornthwaite \& M. M. Kazmer (Eds.), Learning, culture and community in online education: Research and practice (pp. 111-126). New York: Peter Lang.

Kazmer, M. M., \& Haythornthwaite, C. (2004). Juggling multiple social worlds: Distance students online and offline. In C. Haythornthwaite \& M. M. Kazmer (Eds.), Learning, culture and community in online education: Research and practice (pp. 89-109). New York: Peter Lang.

Koschmann, T. D. (1996). Paradigm shifts and instructional technology: An introduction. In T. D. Koschmann (Ed.), CSCL: Theory and practice of an emerging paradigm (pp. 1-23). Mahwah, NJ: Erlbaum. 
Macpherson, A., Elliott, M., Harris, I., \& Homan, G. (2004). E-learning: Reflections and evaluation of corporate programmes. Human Resource Development International, 7(3), 295-313.

Murphy, H. L. (2001). E-learning put to the test. Crain's Chicago Business, 24(35), SR1, SR11. Nielsen, J. (1993). Usability engineering. Boston: Academic Press.

Patton, M. Q. (2002). Qualitative research and evaluation methods (3rd ed.). Thousand Oaks, CA: Sage.

Picciano, A. G. (2002). Beyond student perceptions: Issues of interaction, presence, and performance in an online course. Journal of Asynchronous Learning Networks, 6(1), 2140.

Poole, D. M. (2000). Student participation in a discussion-oriented online course: A case study. Journal of Research on Computing in Education, 33(2), 162-177.

Richardson, J. C., \& Swan, K. (2003). Examining social presence in online courses in relation to students' perceived learning and satisfaction. Journal of Asynchronous Learning Networks, 7(1), 68-88.

Rourke, L., Anderson, T., Garrison, D. R., \& Archer, W. (2001). Assessing social presence in asynchronous text-based computer conferencing. Journal of Distance Education, 14(2), 50-71.

Salmon, G. (2003). E-moderating: The key to teaching and learning online (2nd ed.). New York: RoutledgeFalmer.

Salopek, J. J. (2004). The top 24. T+D, 58(10), 28-65.

Schwandt, T. A. (2000). Three epistemological stances for qualitative inquiry: Interpretivism, hermeneutics, and social constructionism. In N. K. Denzin \& Y. S. Lincoln (Eds.), Handbook of qualitative research (2nd ed., pp. 189-213). Thousand Oaks, CA: Sage.

Schwandt, T. A. (2001). Dictionary of qualitative inquiry (2nd ed.). Thousand Oaks, Calif.: Sage.

Smith, P. J. (2006). Technical rationality and professional artistry in HRD practice. Human Resource Development International, 9(2), 271-281.

Stake, R. E. (1995). The art of case study research. Thousand Oaks, CA: Sage.

Sutton, L. A. (2001). The principle of vicarious interaction in computer-mediated communications. International Journal of Educational Telecommunications, 7(3), 223242.

Swan, K., \& Shea, P. (2005). The development of virtual learning communities. In S. R. Hiltz \& R. Goldman (Eds.), Learning together online: Research on asynchronous learning (pp. 239-260). Mahwah, NJ: Erlbaum.

Waddill, D. D. (2006). Action e-learning: An exploratory case study of action learning applied online. Human Resource Development International, 9(2), 157-171.

Waight, C. L. (2005). Exploring connections between human resource development and creativity. Advances in Developing Human Resources, 7(2), 151-159. 


\section{Author Note}

Funding for this research was provided by a grant from the Pi Chapter of Phi Delta Kappa. I thank Angela Benson, Robert Stake, Peter Kuchinke, and Steven Aragon for invaluable guidance on this project. Also, I am deeply grateful to the program staff and course participants that made this study possible. 